\title{
miR-19 in blood plasma reflects lung cancer occurrence but is not specifically associated with radon exposure
}

\author{
OLGA BULGAKOVA $^{1}$, DINARA ZHABAYEVA ${ }^{1}$, ASSIYA KUSSAINOVA ${ }^{1}$, \\ ALESSANDRA PULLIERO $^{2}$, ALBERTO IZZOTTI ${ }^{2}$ and RAKHMETKAZHI BERSIMBAEV ${ }^{1}$ \\ ${ }^{1}$ Department of General Biology and Genomics, Institute of Cell Biology and Biotechnology, \\ L.N. Gumilyov Eurasian National University, Astana, Akmola 010008, Kazakhstan; \\ ${ }^{2}$ Department of Health Sciences, University of Genoa, Genoa, I-16132 Liguria, Italy
}

Received July 19, 2017; Accepted December 21, 2017

DOI: $10.3892 / \mathrm{ol} .2018 .8392$

\begin{abstract}
Radon is one of the most powerful carcinogens, particularly in terms of lung cancer onset and development. miRNAs may be considered not only as markers of the ongoing tumorigenesis but also as a hallmark of exposure to radiation, including radon and its progeny. Therefore, the purpose of the present study was to estimate the value of plasma miR-19b-3p level as the prospective marker of the response to radon exposure in lung cancer pathogenesis. A total of 136 subjects were examined, including 49 radon-exposed patients with lung cancer, 37 patients with lung cancer without radon exposure and 50 age/sex matched healthy controls. Total RNA from blood samples was extracted and used to detect miR-19b-3p expression via reverse transcription quantitative-polymerase chain reaction. The $2^{-\Delta \Delta \mathrm{Cq}}$ method was used to quantify the amount of relative miRNA. The plasma level of $\mathrm{p} 53$ protein was determined using a Human p53 ELISA kit. Plasma miR-19b-3p level was significantly higher in the patients with lung cancer groups, compared with the healthy control group $(\mathrm{P}<0.0001)$. No other statistically significant differences were determined in the expression level of plasma miR-19b-3p between patients diagnosed with lung cancer exposed to radon and not exposed to radon. The expression level of free circulating miR-19b-3p was higher in the group of non-smoking patients with lung cancer, compared with smokers with lung cancer. The miR-19b-3p was 1.4-fold higher in non-smokers than in smokers $(\mathrm{P}<0.05)$. No association between plasma levels of p53 protein and miR-19b-3p freely circulating in patients with lung cancer was observed. No other statistically significant differences were determined in the plasma p53 protein level between patients diagnosed with lung cancer exposed and not exposed to radon.
\end{abstract}

Correspondence to: Professor Rakhmetkazhi Bersimbaev, Department of General Biology and Genomics, Institute of Cell Biology and Biotechnology, L.N. Gumilyov Eurasian National University, 2 Satpaev Street, Astana, Akmola 010008, Kazakhstan E-mail: ribers@mail.ru

Key words: miRNA, lung cancer, biomarker, radon, p53
These results indicated that detection of miR-19b-3p levels in plasma potentially could be exploited as a noninvasive method for the lung cancer diagnostics. However, this miRNA is not suitable as the precise marker for radon impact.

\section{Introduction}

Lung cancer causes almost 1.3 million mortalities/year globally (1). Cigarette smoke and radon exposure are the major risk factors for lung cancer (2). Primary prevention is fundamental in lung cancer, which is a tumor characterized by a long latency period (3). Circulating miRNAs may be proposed as biomarkers for diagnosis, prognosis or monitoring curative effects in various cancer types, including lung cancer (4). In cells, miRNAs are present as short (18-22 nucleotides), non-coding molecules involved in post-transcriptional gene regulation, mRNA degradation and/or translation inhibition (5). Aberrant expression of miRNAs has been established in diverse tumor types, including hepatocellular carcinoma (6), breast (7), stomach (8), prostate (9) and lung cancer (10).

A numbers of studies have demonstrated that increased expression of miR-19 confers negative prognosis for patients with lung cancer (11-13). According to these studies, the miR-19 family is responsible for epithelial-mesenchymal transformation of cells, which, in turn, further facilitates the processes of cell migration and invasion.

Recent data indicated that miRNAs are engaged in the regulation of cellular processes induced by radiation and, consequently, miRNAs can potentially be used as biomarkers to assess the degree of exposure to radiation in humans (14). There is evidence that the expression profile of a number of miRNAs, including miR19b-3p in human bronchial epithelium BEAS2B cells, have been altered upon exposure to radon (15).

A key role in maintaining the genome stability pertains to p53, including response to damage caused by radiation (16). TP53 mutation was identified in the development of tumors of a number of localizations, including lung cancer (17). Specific 'hotspot' mutations in cancer-relevant genes have been described in radon-induced lung cancer (16,18-20).

Different studies have indicated that TP53 can directly suppress the expression of oncogenic miRNAs, and as a transcription factor, can activate the expression of oncosuppressor 
miRNAs (21-23). However, the latest data also indicated the presence of miRNA-mediated post-transcriptional regulation of TP53 in mammalian cells (24). Fan et al (24) have demonstrated that TP53 is the target of miR-19b and the overexpression of miR-19b in cancer cells leads to a decrease in the level of the p53 protein and its targets, Bax and p21 proteins.

Nevertheless, despite the copious amounts of evidence supporting the association between p53 and miRNA in lung cancer, the pathogenic mechanisms underlying this process remain largely unclear particularly concerning the epigenetic modulation. This is particularly true for radon-induced lung cancer $(25,26)$.

The aim of the present study was to determine the alterations in free circulating miR-19b and the level of $\mathrm{p} 53$ protein in the plasma of patients with lung cancer exposed to high doses of radon.

\section{Materials and methods}

Study design and population. A total of 136 subjects was examined, including: i) 49 radon-exposed patients with lung cancer (RLC); ii) 37 patients with lung cancer without radon exposure (LC); and iii) 50 healthy controls (C). The radon-exposed patients with lung cancer comprised 39 males and 10 females with a mean age of $67.8 \pm 1.78$ years. The group of lung cancer patients without radon exposure consisted of 31 males and 6 females with a mean age of 57.42 \pm 2.34 years. Healthy control was represented by 39 males and 11 females with a mean age of $60.7 \pm 1.96$ years.

All patients with primary lung cancer were diagnosed between April 2015 and September 2016 at the Astana Oncology Center (Astana, Kazakhstan) and at the Akmola Region Oncology Hospital (Kokshetau, Kazakhstan). All cases were newly diagnosed, previously untreated and histologically confirmed. Clinical stage was classified according to the sixth edition of the Tumor-Node-Metastasis classification of the International Union Against Cancer (27). Controls were matched for sex, age and smoking status to patients with lung cancer, according to characteristics of subjects which are reported in Table I. At recruitment, each participant was interviewed to obtain detailed information on age, life history of tobacco use and occupational activities.

All information regarding participants was rendered anonymous following data and blood sample collection. Informed consent was obtained from each study participant prior to interview and blood collection. The present study was approved by the Ethical Committee of the Semey State Medical University (Semey, Kazakhstan; approval no. 2).

RNA extraction from blood. A $10 \mathrm{ml}$ sample of whole peripheral blood was collected from each subject into EDTA containing tubes. Blood was centrifuged at 3,000 x g for $10 \mathrm{~min}$ at room temperature and supernatant stored in aliquots at $-80^{\circ} \mathrm{C}$. Total RNA from $200 \mu \mathrm{l}$ plasma was isolated using the MiRCURY ${ }^{\mathrm{TM}}$ RNA Isolation kit-Biofluids (cat no. 300112; Exiqon A/S, Vedbaek, Denmark), in accordance with the manufacturer's protocol. The amount and purity of extracted RNA were evaluated using a fiber optic spectrophotometer (Nanodrop $^{\text {TM }}$ ND-1000; Nanodrop Technologies; Thermo Fisher Scientific, Inc., Waltham, MA, USA) in accordance with the manufacturer's protocols, and the 230/260 $(<0.50)$ and 260/280 (>1.85) absorbance ratios were calculated. The RNA structural integrity was evaluated by capillary electrophoresis using a RNA bioanalyzer (Bioanalyzer Agilent 2100; Agilent Technologies, Inc., Santa Clara, CA, USA) equipped with a RNA oligonucleotide chip (RNA 6000 Nano Ladder Chip; Agilent Technologies, Inc.). The miRNA amounts were accurately standardized among blood serum samples for microarray and quantitative polymerase chain reaction (qPCR) analyses using the Qubit ${ }^{\mathrm{TM}}$ 3.0 Fluorometer (Thermo Fisher Scientific, Inc.).

miR-19 analysis by $q P C R$. The expression levels of miR-19b-3p was determined by evaluating the level of fluorescence emitted by SYBR ${ }^{\circledR}$ Green tracer (cat no. 203403; Exiqon A/S, Denmark). SYBR-Green fluorescent tracer was used to identify PCR amplicons whose identity was checked by melting curve analysis according to previously published procedures (28). MiRCURY LNA ${ }^{\mathrm{TM}}$ UNIVERSAL RT microRNA PCR kit, including miR-19b-3p-specific primers (cat no. 204450; Exiqon A/S, Vedbaek, Denmark) and primers for the reference gene RNU6B (cat no. 203907; Exiqon A/S) for reverse transcription (RT)-qPCR, was used to amplify miRNAs. cDNAs were prepared using Universal synthesis kit (cat no. 203301; Exiqon A/S) according to the manufacturer's instructions. PCR amplification was performed in the CFX96 Touch $^{\mathrm{TM}}$ Real-Time PCR Detection System (Bio-Rad Laboratories, Inc., Hercules, CA, USA). Each reaction was carried out using $4 \mu \mathrm{l}$ of cDNA, $1 \mu \mathrm{l}$ of PCR primer mix and $5 \mu \mathrm{l}$ SYBR-Green PCR Master mix (cat nos. 204450 and 203403 respectively; Exiqon A/S, Denmark) in a final $10 \mu \mathrm{l}$ volume. The RT-qPCR was performed at $95^{\circ} \mathrm{C}$ for $10 \mathrm{~min}$ for one cycle, followed by 40 cycles of $95^{\circ} \mathrm{C}$ for $10 \mathrm{sec}$ and $60^{\circ} \mathrm{C}$ for $60 \mathrm{sec}$. The specificity of PCR products was evaluated by the melting curve analysis. Gene expression was normalized to RNU6B. All reactions were carried out in triplicate, and the $2^{-\Delta \Delta \mathrm{Cq}}$ method $\left(\Delta \mathrm{Cq}=\mathrm{CT}_{\mathrm{miR}}-\mathrm{CT}_{\mathrm{U} 6}\right)$ was used to quantify the relative miRNA amount (29).

Exposure assessment. Measurement of radon activity was conducted in accordance with the Rapid Measurement Method of radon and thoron (30) using a Canary 222 Digital Electronic Radon Gas Monitor (LR-03) radiometer (Corentium AS, Oslo, Norway). The measurement of radon concentration was carried out at the homes of recruited patients in rooms previously unventilated for at least $24 \mathrm{~h}$. In each room, radon in the air was measured for seven days and the average value was used for further calculations.

The annual effective dose $(\mathrm{H})$ was calculated according to the formula (30): $\mathrm{H}(\mathrm{mSv} / \mathrm{y})=\mathrm{C} \times \mathrm{F} \times \mathrm{O} \times \mathrm{T} \times \mathrm{D}$; where $\mathrm{C}$ stands for the average radon concentration $\mathrm{Bq} / \mathrm{m}^{3}, \mathrm{~F}$ is the equilibrium factor for indoor that is set as $0.4, \mathrm{O}$ is the occupancy factor taken as $0.8, \mathrm{~T}$ is time in $\mathrm{h}$ in a year $(8,760 \mathrm{~h} / \mathrm{y})$ and $\mathrm{D}$ is the dose conversion factor, $1.4 \times 10^{-8} \mathrm{~Sv} / \mathrm{Bq} / \mathrm{m}^{3} \mathrm{~h}$.

Determination of p53 protein in plasma. The plasma level of p53 protein was determined using an ELISA kit (Human p53 ELISA kit; cat no. ab46067; Abcam, Cambridge, UK). The samples were added to 96-microtiter wells pre-coated with the p53 monoclonal antibody from the kit and incubated at room 
Table I. Characteristics of the subjects participating in the present study.

\begin{tabular}{llcccc}
\hline Characteristics & \multicolumn{1}{c}{ Variables } & LC, $\mathrm{n}=37(\%)$ & RLC, $\mathrm{n}=49(\%)$ & P-value & C, $\mathrm{n}=50(\%)$ \\
\hline Sex & Male & $31(84)$ & $39(80)$ & 0.78 & $39(78)$ \\
& Female & $6(16)$ & $10(20)$ & & $11(22)$ \\
Age, years & $\leq 60$ & $18(49)$ & $12(24)$ & 0.04 & $21(42)$ \\
& $>60$ & $18(49)$ & $33(67)$ & & $29(58)$ \\
Stage of cancer & Unknown & $1(3)$ & $4(8)$ & & - \\
& I & $7(19)$ & $4(8)$ & 1.0 & - \\
& II-IV & $22(59)$ & $35(71)$ & & - \\
Smoking status & Unknown & $8(22)$ & $10(20)$ & - & $41(82)$ \\
& Non-smokers & $9(24)$ & $24(49)$ & 0.01 & $8(16)$ \\
& Smokers & $21(57)$ & $13(27)$ & & $12(2)$
\end{tabular}

aPatients having stopped smoking $<6$ months ago. RLC, patients with lung cancer exposed to radon; LC, patients with lung cancer without exposure to radon; $\mathrm{C}$, control group.

temperature for $2 \mathrm{~h}$. Samples and biotinylated p53 monoclonal antibody were incubated for $1 \mathrm{~h}$ at room temperature. Following washing three times with 200X Wash buffer from the kit, the enzyme Streptavidin-HRP (also from the Human p53 ELISA kit), which binds the biotinylated antibody, was added and incubated for $30 \mathrm{~min}$ with washes performed three times with 200X Wash buffer from the kit according to the protocol of the manufacturer. Chromogen TMB (3,3',5,5;-tetramethylbenzidine) substrate solution was added inducing a colored reaction product. The absorbance at $450 \mathrm{~nm}$ of each well was determined using a microplate reader (Asys Expert microplate reader; Biochrom, Ltd., Cambridge, UK). All samples were measured in triplicate.

Determination of cotinine in plasma. In order to verify smoking status of the individuals, blood plasma cotinine was utilized as a marker. The cotinine level was determined using an ELISA kit (Cotinine ELISA kit; cat no. KA0930; Abnova, Taipei, Taiwan) performed according to the manufacturers' protocols. Briefly, samples and cotinine enzyme conjugate were added to the wells coated with anti-cotinine antibody and horse peroxidase colorimetric reaction performed. Unbound cotinine and cotinine enzyme conjugate were washed three times with $300 \mu 1$ 1X Wash Buffer, also from the Cotinine ELISA kit. The intensity of color (absorbance wavelength $450 \mathrm{~nm}$ ) was inversely proportional to the concentration of cotinine in the samples. A standard curve was prepared associating color intensity with the concentration of the cotinine.

Statistical analysis. All statistical analyses were performed using GraphPad Prism 6 software (GraphPad Software, Inc., La Jolla, CA, USA). All data are presented as mean \pm SD. Differences between groups were assessed using the Tukey's post hoc test after one-way analysis. $\mathrm{P}<0.05$ was considered to indicate a statistically significant difference; ${ }^{*} \mathrm{P}<0.05$; ${ }^{* *} \mathrm{P}<0.01 ;{ }^{* * *} \mathrm{P}<0.001$; and ${ }^{* * * *} \mathrm{P}<0.0001 . \chi^{2}$ was used to calculate the statistical significance in Table I.

\section{Results}

Effective annual radon exposure dose and decay product inhalation. The overall exposure to radon evaluated at the homes of monitored subjects is reported in Table II. The table represents the home addresses of the patients with lung cancer living on the territory with a level above the permissible concentration, where radon levels were measured, and also demonstrated a level of equivalent equilibrium volume activity of radon (EEVA) and effective exposure dose for the population.

According to the generally accepted opinion in the world scientific community, the distribution of EEVA parameters obeys the lognormal law (30); therefore, the median value was used as the average value for calculating the exposure power of radon and its decay products. The characteristics of the data array and the parameters of the lognormal distribution are depicted in Table III. Thus, the average effective annual dose for patients diagnosed with lung cancer living in the areas with a high level of EEVA was $4.55 \mathrm{mSv} / \mathrm{y}$. Participants in the study selected for control groups (C and LC) lived in areas with a low level of EEVA. These areas were determined according to the results reported in a previous study (15). The EEVA data used to calculate the average effective annual dose for participants in the control group study (C and LC) are depicted in Table IV. Thus, the average effective annual dose for study participants living in areas with a low level of EEVA was $0.88 \mathrm{mSv} / \mathrm{y}$.

miR-19b-3p expression level in the plasma of patients with lung cancer with and without radon exposure. The total circulating miRNA was isolated from blood plasma using the protocol aforementioned and divided to three groups: Patients diagnosed with lung cancer living in areas with a radon concentration below $200 \mathrm{~Bq} / \mathrm{m}^{3}$ for $\geq 5$ years; patients diagnosed with lung cancer who had been exposed to high doses of radon for 5 years; and a control group consisting of healthy individuals, who did not have pulmonary pathology and lived in a EEVA area with $<200 \mathrm{~Bq} / \mathrm{m}^{3}$. The expression levels of miRNA-19b-3p 
Table II. Overall air radon exposure of the premises and the effective exposure dose for the population.

Facility index where EEVA measurements were taken

Average value of EEVA, $\mathrm{Bq} / \mathrm{m}^{3}$

1

2

3

4

5

6

7

8

9

10

11

12

13

14

15

16

17

18

19

20

21

22

23

24

25

26

27

28

29

30

31

32

33

34

35

36

37

38

39

40

41

42

43

44

45

46

47

\begin{tabular}{|c|c|c|c|}
\hline \multirow{3}{*}{$\begin{array}{l}\text { rage value } \\
\text { f EEVA, } \\
\mathrm{Bq} / \mathrm{m}^{3}\end{array}$} & \multirow{3}{*}{$\begin{array}{c}\text { Annual effective } \\
\text { dose, } \mathrm{mSv} / \mathrm{y}\end{array}$} & Parameters & Values \\
\hline & & Number of measurements & 47 \\
\hline & & Minimum, $\mathrm{Bq} / \mathrm{m}^{3}$ & 8 \\
\hline 529 & 20.76 & Maximum, $\mathrm{Bq} / \mathrm{m}^{3}$ & 716 \\
\hline 51.2 & 2 & Median, Bq/m & 110 \\
\hline
\end{tabular}

Table III. Number of measurements and EEVA study results for areas with high levels of radon.

1.59

3.32

5.22

4.55

5.3

2.12

1.73

24.2

4.63

4.67

3.06

7.69

28.1

17.66

10.87

7.57

13.74

8.24

7.42

21.9

16.48

0.67

5.49

2.75

0.71

1.73

6.99

1.18

0.43

2.94

2.51

1.41

12.36

20.6

0.31

7.46

0.59

0.39

2.55

15.92

2.94

4.12

19.82

1.41

0.86

EEVA, equivalent equilibrium volume activity.

Table IV. Number of measurements and EEVA study results for areas with permissible radon concentrations.

\begin{tabular}{lc}
\hline Parameters & Values \\
\hline Number of measurements & 86 \\
Minimum, $\mathrm{Bq} / \mathrm{m}^{3}$ & 2 \\
Maximum, Bq $/ \mathrm{m}^{3}$ & 135 \\
Median, $\mathrm{Bq} / \mathrm{m}^{3}$ & 22.5 \\
\hline
\end{tabular}

in all three groups were depicted in Fig. 1. miR-19b-3p expression levels in patients of the RLC group were 6.5 times higher $(\mathrm{P}<0.0001)$ than in the $\mathrm{C}$ group. miR-19 expression levels in the LC group was 6.9 times increased $(\mathrm{P}<0.0001)$, compared with those detected in the $\mathrm{C}$ group. Comparative analysis of the relative miR-19b-3p expression level in the RLC group vs. the LC group indicated that the miR-19b-3p expression profile in both groups did not differ significantly.

miR-19b-3p expression level in the plasma associated with smoking habits. The association of miR-19b-3p expression with smoking status was examined. The results of the present study demonstrated that miR-19b-3p expression levels do not differ in patients with lung cancer with or without radon exposure, and these groups were combined into one 'patients with lung cancer' group. This group was divided into current smokers and non-smokers regardless of radon exposure. Cotinine levels $<10 \mathrm{ng} / \mathrm{ml}$ was considered as an indicator of the absence of current smoking.

The 'Smokers' group consisted of 34 people, and the 'Non-smokers' group 33 people. Former smokers (subjects having stopped smoking $<6$ months ago) have been excluded from any of these groups (19 subjects). Furthermore, healthy control group (50 subjects) have been not included to this particular analysis due to, according to the previous experiments, miR-19b-3p expression level was significantly lower in the control group than in two groups with lung cancer diagnosis, that is, these groups are incompatible. As it can be observed from Fig. 2, the level of free circulating miR-19b-3p is higher in plasma in the group of non-smoking patients with lung cancer, compared with smokers. The mean plasma miR-19b-3p expression level was $6.45 \pm 0.4$ in the 'Non-smokers' group in comparison with the 'Smokers' group, where the mean miR-19b-3p expression level was $4.74 \pm 0.5$, miR-19 being 1.4-fold higher in non-smokers than in smokers $(\mathrm{P}<0.05)$. 
Table V. Level of p53 protein in the plasma of RLC, LC and C.

\begin{tabular}{lcccccc}
\hline Subjects & $\mathrm{n}$ & Min, $\mathrm{U} / \mathrm{ml}$ & Max, $\mathrm{U} / \mathrm{ml}$ & Med, U/ml & Mean, U/ml & P-value \\
\hline RLC & 49 & 0.1 & 126.94 & 13 & 18.76 & $<0.01$ \\
LC & 37 & 5.17 & 36.81 & 15.24 & 17.92 & $<0.05$ \\
C & 50 & 1.96 & 39.64 & 6.49 & 8.646 &
\end{tabular}

RLC, patients with lung cancer exposed to radon; LC, patients with lung cancer without exposure to radon; C, control group.

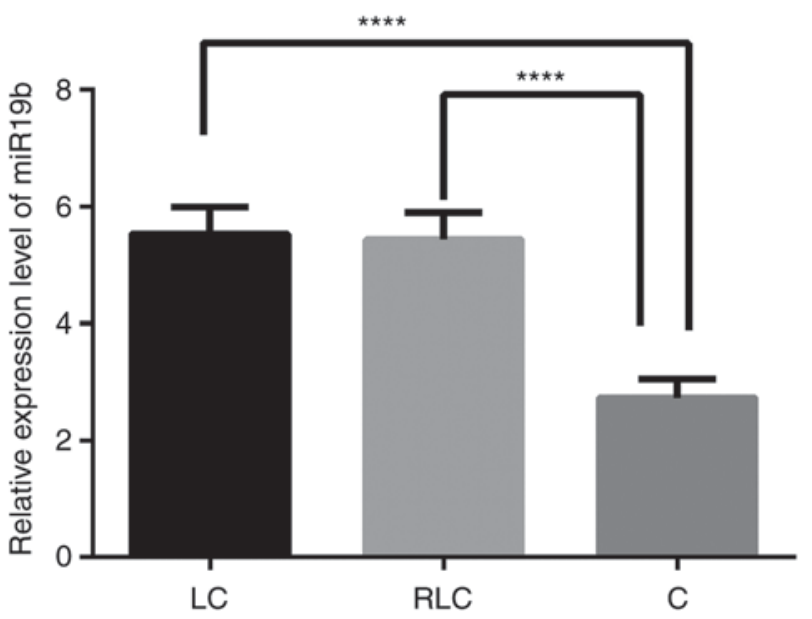

Figure 1. Relative expression level of miR-19b-3p in the plasma of RLC and LC in comparison with $C .{ }^{* * * *} \mathrm{P}<0.0001$ vs. C. RLC, patients with lung cancer exposed to radon; LC, patients with lung cancer without exposure to radon; $\mathrm{C}$, control group.

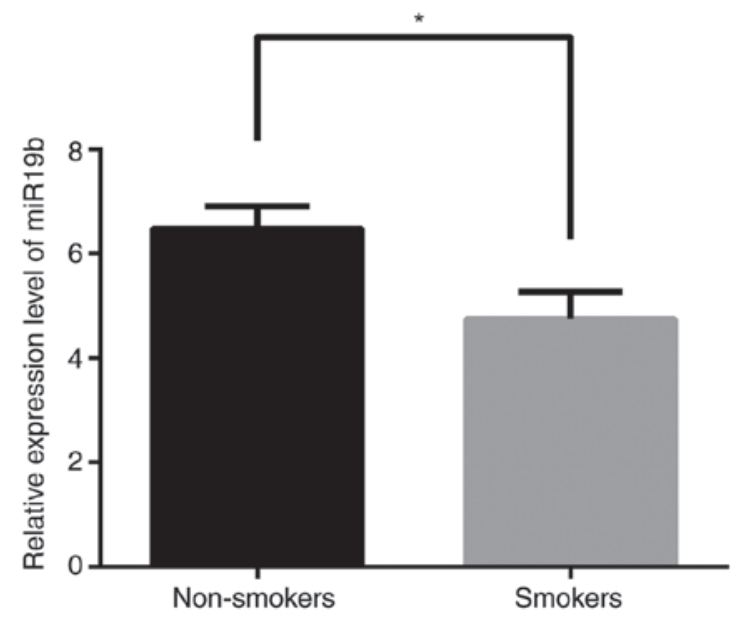

Figure 2. Relative miR-19b-3p expression level in the plasma of patients with lung cancer depending on the smoking status. "P $<0.05$ vs. Smokers.

p53 protein in plasma of patients with lung cancer as associated with radon exposure. The results of the p53 protein measurement in plasma are given in Table V representing minimum, maximum, median and mean values. p53 protein levels of the $\mathrm{LC}$ were determined in a range from 5.17-36.81 U/ml, with a median value of $15.24 \mathrm{U} / \mathrm{ml}$ and the mean of $17.92 \pm 1.53 \mathrm{U} / \mathrm{ml}$. RLC demonstrated the highest plasma p53 in the present study. In this group, the plasma levels of p53 had a range from 0.1-26.94 $\mathrm{U} / \mathrm{ml}$, median value of $13.0 \mathrm{U} / \mathrm{ml}$ and mean of $18.76 \pm 3.31 \mathrm{U} / \mathrm{ml}$. The $\mathrm{p} 53$ protein has not been detected in plasma in $16 \%$ of the samples from $\mathrm{C}$ group. In $84 \%$ of samples from group C, the plasma levels of p53 were determined to range from 1.96-39.64 U/ml, with a median of $6.49 \mathrm{U} / \mathrm{ml}$ and mean value of $8.646 \pm 1.25 \mathrm{U} / \mathrm{ml}$. The p53 plasma levels in the LC group were 2 times higher than in those of healthy subjects $(\mathrm{P}<0.05$; Fig. 3$)$. The p53 protein level was also 2 times higher in radon-exposed patients with lung cancer than in healthy volunteers $(\mathrm{P}<0.01)$. There were no significant differences in p53 protein concentrations between LC and RLC $(\mathrm{P}=0.265)$. However, there was no association between the level of miR-19b-3p and the plasma p53 level in patients with lung cancer, as indicated via regression analysis $(\mathrm{r}=0.06 ; \mathrm{P}=0.24)$.

\section{Discussion}

Recent studies have reported that non-coding RNA (ncRNA) may serve a critical role in regulating different cancer types $(31,32)$. These ncRNAs are divided into housekeeping ncRNAs and regulatory ncRNAs (33). The regulatory ncRNAs have emerged as critical regulators of gene expression in normal and disease states (34). This heterogeneous group depending on their size can be divided into lncRNAs ( $\geq 200$ nucleotides) and small ncRNAs ( $<200$ nucleotides) (35). miRNAs represent the most studied small ncRNAs. These molecules predominantly bind to 3'-UTRs of mRNAs to mediate post-transcriptional gene silencing (36). A number of studies have identified aberrant miRNA expression in different types of cancer (35). Circulating miRNAs, passively leaked or actively transported outside cells, can be stably detected in blood and may be proposed as biomarkers for diagnosis, prognosis or monitoring curative effect in various cancer types, including lung cancer (37). Since miRNAs are involved in the development and progression of lung cancer, there is a particular interest in miRNAs not only as novel biomarkers but also as potential tools for treatment (38).

In the present study, changes in the level of miR-19b-3p expression were analyzed, which serve a significant role in the development of a number of cancer types $(39,40)$, as well as in metastasis (41) and tumor response to drug therapy (42). A miRNA panel including miR-19b-3p in peripheral plasma was identified and proposed as a biomarker in diagnosis of adenocarcinoma lung cancer as reported by Zhou et al (43). Furthermore, obtained results are consistent with the previous data of $\mathrm{Li}$ et al (41), who discovered that miR-19b expression was significantly higher in lung adenocarcinoma cell lines 
(A549), compared with the cell line of human lung epithelial cells. The present study has also demonstrated that a high level of miR-19b expression can promote the proliferation and migration of lung cancer cells (44). Additionally, miR-19-3p, miR-21-5p and miR-221-3p were significantly upregulated in exosomes extracted from peripheral plasma of patients with lung adenocarcinoma (43).

Epidemiological studies have provided strong evidence for associations between exposure to environmental factors and lung cancer $(45,46)$. Risk factors for lung cancer include: Smoking; exposure to secondhand smoke; exposure to asbestos (47); and other carcinogens. Radon is the second leading cause of lung cancer among smokers and the leading cause among nonsmokers (2). A high level of radon has been observed in the North and East areas of Kazakhstan due to the natural radiation sources and the long-term and large-scale mining of uranium (48). Currently, there is no clear insight of the molecular mechanism underlying radon induced lung cancer (49).

Accordingly, the miRNA profile revealed a radon-induced change in the miR-19b-3p expression in bronchial epithelial cells (BEAS2B). The level of miR-19b-3p expression increased by 17 times upon radon impact (15). Therefore, it can be assumed that this miRNA could be involved in the pathogenesis of radon-induced lung cancer. However, comparative analysis of miR-19b-3p blood expression level in RLC and LC reveals no significant difference between the two groups. Thus, the obtained results indicated that miR19b-3p serves an important role in the malignant neoplasm development. However, according to the present study, this miRNA is inappropriate to be utilized as a hallmark of radon impact.

Another important aspect of the given study is the effect of smoking as the main risk factor for the development of lung cancer and on the level of miR-19 expression (50). It is logical to assume that if tobacco smoke is a carcinogen, and therefore the level of oncomir in smoking patients with lung cancer diagnosis should increase. However, in the present study the obtained results demonstrated the opposite. Thus, in the smoking group of patients with lung cancer, the expression level of miR-19b-3p was significantly lower than in the group of non-smokers. It is possible that this is not a specific reduction in the miR-19b-3p expression since tobacco smoke provokes a general decrease in all freely circulating miRNAs due to the inhibitory effect on the main enzyme of miRNA biogenesis, DICER (51). Furthermore, it has been reported that the alteration of miRNA expression induced by cigarette smoke has opposite effects in the lungs and blood, with the lungs downregulating miRNAs and miRNAs being upregulated in blood (52). This situation is associated with the inhibition of DICER processing induced by cigarette smoke exposure, which causes a blockage in miRNA maturation and release from cells into the blood stream of miRNA precursor in the absence of their mature counterpart (53).

miRNAs downregulated by mainstream cigarette smoke are miR-19b and miR-292, which are involved in the regulation of DICER, a key molecule in miRNA biogenesis, as demonstrated by Balansky et al (54). However, in the present study there are a number of limitations: First, the level of miRNA circulating freely in the blood plasma was analyzed. The level of free circulating miRNAs can differ significantly from

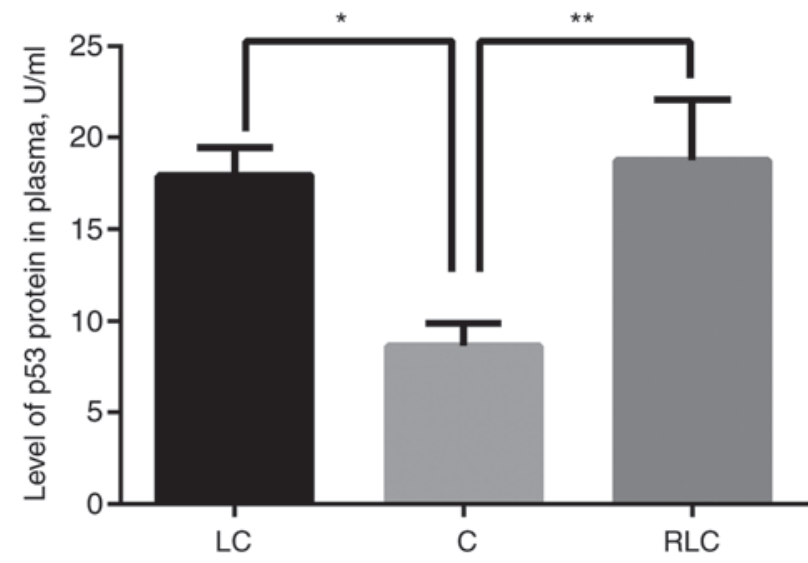

Figure 3. Level of plasma p53 of RLC and LC in comparison with $\mathrm{C}$. ${ }^{*} \mathrm{P}<0.05$ LC vs. $C,{ }^{* *} \mathrm{P}<0.01 \mathrm{RLC}$ vs. $\mathrm{C}$, patients with lung cancer exposed to radon; LC, patients with lung cancer without exposure to radon; C, control group.

the level of the same miRNAs in the tissues due to different types of mammalian tissues varying in the profile of miRNAs expressed in them (55). An example of this case is let-7 miRNA, which serves a significant role in the embryonic development of the lung, and the expression of this miRNA remains at a high level in the postembryonic period (56). As Mendell (57) depicted, the miR-17-92 miRNA cluster, which includes miR-19, serves a crucial role in the embryonic development of the heart, lungs and immune system. Furthermore, the loss of the function of the miR-17-92 cluster leads to a decrease in the size of embryos and the immediate postnatal mortality of all animals (57). This is possibly due to pronounced lung hypoplasia and interventricular septum defects in the hearts of mice devoid of miR-17-92 (57).

The observations aforementioned are consistent with an earlier demonstration that miR-17-92 miRNA clusters usually have a high level of expression in the embryonic lung, and later its levels decrease as the mice matures (58). Furthermore, the transgenic expression of these miRNAs specifically in the pulmonary epithelium leads to severe developmental defects with increased proliferation and inhibition of epithelial cell differentiation (58). Despite the fact that exposure to tobacco smoke experiments in animal models lead to a decrease in body weight and have in general negative effect on cell proliferation and survival, an opposite pattern has been observed in target tissues, including lungs distinguished by hyperplasia of pulmonary tissue (54). Considering the aforementioned, it appears necessary to investigate the tissue-specific miR-19b-3p profile in the lungs of smokers and non-smokers to improve the understanding of the role of this miRNA in the development of lung cancer induced by smoking. The present study has demonstrated that the level of miR-19b-3p circulating in the blood plasma significantly decreases in smokers with lung cancer, and this is consistent with previous data, indicating the negative effect of tobacco smoke on proliferative activity in the body as a whole $(59,60)$.

miR-19 is a key member of the miR-17/92 cluster, which targets several critical apoptosis associated genes, including TP53 (24). Fan et al (24) demonstrated that when miR-19b is transfected into HeLa cells, following $48 \mathrm{~h}$, the $\mathrm{p} 53$ protein level is reduced by $50 \%$, while the mRNA level remains unchanged. 
Indeed, miR-19b directly targets $\mathrm{p} 53$ by base-pairing to its 3'UTR The TP53 gene was the first tumor-suppressor gene to be identified. The p53 network, which present in all cells of the organism is normally 'off' (61). In the absence of damage to the genetic apparatus, the p53 protein is in an inactive state, and when DNA lesions occur, it becomes activated (62). The p53 protein is also activated by stimuli that remind those damages when p53 is active or are a signal regarding the unfavorable state of the cell (stress state) (63). The function of the p53 protein is to remove from the pool of replicating oncogenetic cells (62). Consequently, it can be assumed that one of the mechanisms underlying the lung cancer development is a decrease in the level of the p53 protein due to targeting its mRNA by miR-19b-3p and is mediated by this process of prevention of apoptosis in cancer cells.

In the present study, utilizing the Human p53 ELISA kit, it was determined that the level of the p53 protein in plasma of patients with lung cancer exposed to high doses of radon as well as in those individuals living in areas with a permissible concentration of EEVA, compared with the control group consisting of healthy people. The results of the present study have revealed that the level of p53 is significantly higher in both groups of patients diagnosed with lung cancer, while in a number of samples of healthy people it has not been detected at all. This data does not contradict the available data (64). According to a previous study (65), the level of antibodies against p53 in the blood serum increases with any pathology of the lung not only in malignant but even in benign tumors (65).

The present study paid close attention to two aspects. Firstly, whether there was a association between the p53 level and miR-19b-3p circulating freely in the blood plasma; additionally, the second aspect has concerned the issue of the effect of plasma p53 level on radon and its progeny.

The present study revealed no association between the plasma p53 and miR-19b-3p levels freely circulating in the blood plasma in patients with lung cancer. Thus, in both cases, the level of p53 protein and miR-19b-3p has been determined in the blood plasma and not in the lung tissue, so it cannot be concluded that these two components are not involved in a single mechanism underlying the malignant tumor onset in the lung. In addition, no other statistically significant differences have been determined in the plasma p53 protein level between RLC and LC. Also, the results of the present study are consistent with the data of other authors $(66,67)$. In the studies of Schneider et al (67), no appreciably elevated or diminished p53 protein or anti-p53 antibodies values in serum of Former Uranium Miners was determined. Also, there was no association of these indicators with Working Level Months (WLM). Thereby, plasma p53 protein level is ineffective as a biomarker for the detection of lung cancer associated with radon and its progeny.

Collectively, these studies indicated that miR-19b-3p is not a suitable biomarker for radon-induced lung cancer. Despite the available data in the literature that overexpression of miR-19b observed in human cancer cells lines can diminish p53 protein levels, the present study did not determine any association between the plasma p53 and the miR-19b-3p levels freely circulating in the blood plasma in patients with lung cancer. Furthermore, any changes in the plasma p53 protein levels depending on the effect of radon were not determined.
However, further research for biomarkers including miRNAs will provide a biomonitoring strategy to face health-risk in population living in radon-polluted areas and professionally exposed workers.

\section{Acknowledgements}

The authors thank the Astana Oncology Center and Akmola Region Oncology Hospital for their help in collection of blood samples. The authors are grateful to Dr Tuleutaev Muhtar (Medical Director of the Astana Oncology Center) and Dr Kakabaev Anuar (Sh Ualikhanov Kokshetau State University, Kokshetau, Kazakhstan) for their help in collection of the blood samples.

\section{Funding}

The present study was supported by the projects of Ministry of Education and Science of the Republic of Kazakhstan (grant no. $1258 / \mathrm{GF} 4)$.

\section{Availability of data and materials}

The analyzed data sets generated during the study are available from the corresponding author on reasonable request.

\section{Authors' contributions}

$\mathrm{RB}$, AI provided the study concept and design. RB, OB, AI and AP wrote and revised the manuscript. AP participated in discussion and made a significant contribution to the interpretation of the results. OB, DZ and AK collected the data, and performed the experiments. AK and DZ performed the RNA extraction from blood samples. OB and DZ performed the determination of p53 protein and cotinine in plasma and qPCR. OB and AK performed the radon exposure assessment. OB performed the statistical analyses. The final version of the manuscripts was read and approved by all authors.

\section{Ethics approval and consent to participate}

Informed consent was obtained from each study participant prior to interview and blood collection. The present study was approved by the Ethical Committee of the Semey State Medical University (Semey, Kazakhstan).

\section{Consent for publication}

All information regarding participants was rendered anonymous following data and blood sample collection.

\section{Competing interests}

The authors declare that they have no competing interests.

\section{References}

1. Amin J, Sharif M and Yasmin M: Segmentation and classification of lung cancer: A review. Immunol Endo Metab Age Med Chem 16: 82-99, 2016 
2. Zeeb $\mathrm{H}$ and Shannon F: WHO handbook on indoor radon: A public health perspective. In: World Health Organization. Zeeb H and Shannon F (eds) World Health Organization, Geneva, 3-21; 2009.

3. Ahn YS and Jeong KS: Epidemiologic characteristics of compensated occupational lung cancers among Korean workers. J Korean Med Sci 29: 1473-1481, 2014.

4. Izzotti A, Carozzo S, Pulliero A, Zhabayeva D, Ravetti JL and Bersimbaev R: Extracellular MicroRNA in liquid biopsy: Applicability in cancer diagnosis and prevention. Am J Cancer Res 6: 1461-1493, 2016.

5. Anglicheau D, Muthukumar T and Suthanthiran M: MicroRNAs: Small RNAs with big effects. Transplantation 90: 105-112, 2010

6. Nishida N, Arizumi T, Hagiwara S, Ida H, Sakurai T and Kudo M: MicroRNAs for the prediction of early response to Sorafenib treatment in human hepatocellular carcinoma. Liver Cancer 6: 113-125, 2017.

7. Nassar FJ, Nasr R and Talhouk R: MicroRNAs as biomarkers for early breast cancer diagnosis, prognosis and therapy prediction. Pharmacol Ther 172: 34-49, 2017.

8. Hemmatzadeh M, Mohammadi H, Karimi M, Musavishenas MH and Baradaran B: Differential role of microRNAs in the pathogenesis and treatment of esophageal cancer. Biomed Pharmacother 82: 509-519, 2016.

9. Kumar B and Lupold SE: MicroRNA expression and function in prostate cancer: A review of current knowledge and opportunities for discovery. Asian J Androl 18: 559-567, 2016.

10. Taniwaki M, Daigo Y, Ishikawa N, Takano A, Tsunoda T, Yasui W, Inai K, Kohno N and Nakamura Y: Gene expression profiles of small-cell lung cancers: Molecular signatures of lung cancer. Int J Oncol 29: 567-575, 2006.

11. Wu C, Cao Y, He Z, He J, Hu C, Duan H and Jiang J: Serum levels of miR-19b and miR-146a as prognostic biomarkers for non-small cell lung cancer. Tohoku J Exp Med 232: 85-95, 2014.

12. Li J, Yang S, Yan W, Yang J, Qin YJ, Lin XL, Xie RY, Wang SC Jin W, Gao F, et al: MicroRNA-19 triggers epithelial-mesenchymal transition of lung cancer cells accompanied by growth inhibition. Lab Invest 95: 1056-1070, 2015.

13. Lin Q, Chen T, Lin Q, Lin G, Lin J, Chen G and Guo L: Serum miR-19a expression correlates with worse prognosis of patients with non-small cell lung cancer. J Surg Oncol 107: 767-771, 2013.

14. Chaudhry MA: Radiation-induced microRNA: Discovery, functional analysis, and cancer radiotherapy. J Cell Biochem 115: 436-449, 2014.

15. Cui FM, Li JX, Chen Q, Du HB, Zhang SY, Nie JH, Cao JP, Zhou PK, Hei TK and Tong J: Radon-induced alterations in micro-RNA expression profiles in transformed BEAS2B cells J Toxicol Environ Health A 76: 107-119, 2013.

16. Yngveson A, Williams C, Hjerpe A, Lundeberg J, Söderkvist P and Pershagen G: p53 mutations in lung cancer associated with residential radon exposure. Cancer Epidemiol Biomarkers Prev 8: 433-438, 1999.

17. Deben C, Deschoolmeester V, Lardon F, Rolfo C and Pauwels P: TP53 and MDM2 genetic alterations in non-small cell lung cancer: Evaluating their prognostic and predictive value. Crit Rev Oncol Hematol 99: 63-73, 2016.

18. Vähäkangas KH, Samet JM, Metcalf RA, Welsh JA, Bennett WP, Lane DP and Harris CC: Mutations of p53 and ras genes in radon-associated lung cancer from uranium miners. Lancet 339: 576-580, 1992

19. Taylor JU, Watson MA, Devereux TR, Michels RY, Saccomanno G and Anderson M: p53 mutation hotspot in radon-associated lung cancer. Lancet 343: 86-87, 1994.

20. Lo YM, Darby S, Noakes L, Whitley E, Silcocks PB, Fleming KA and Bell JI: Screening for codon 249 p53 mutation in lung cancer associated with domestic radon exposure. Lancet 345: 60, 1995.

21. Bommer GT, Gerin I, Feng Y, Kaczorowski AJ, Kuick R, Love RE, Zhai Y, Giordano TJ, Qin ZS, Moore BB, et al: p53-mediated activation of miRNA34 candidate tumor-suppressor genes. Curr Biol 17: 1298-1307, 2007.

22. Piovan C, Palmieri D, Di Leva G, Braccioli L, Casalini P, Nuovo G, Tortoreto M, Sasso M, Plantamura I, Triulzi T, et al: Oncosuppressive role of p53-induced miR-205 in triple negative breast cancer. Mol Oncol 6: 458-472, 2012.

23. Liao JM, Cao B, Zhou X and Lu H: New insights into p53 functions through its target microRNAs. J Mol Cell Biol 6: 206-213, 2014.

24. Fan Y, Yin S, Hao Y, Yang J, Zhang H, Sun C, Ma M, Chang Q and Xi JJ: mir-19b promotes tumor growth and metastasis via targeting TP53. RNA 20: 765-772, 2014.
25. Zhang $\mathrm{N}$, Wei $\mathrm{X}$ and $\mathrm{Xu} \mathrm{L}$ : $\mathrm{miR}-150$ promotes the proliferation of lung cancer cells by targeting P53. FEBS Lett 587: 2346-2351, 2013.

26. Talekar M, Trivedi M, Shah P, Ouyang Q, Oka A, Gandham S and Amiji MM: Combination wt-p53 and MicroRNA-125b transfection in a genetically engineered lung cancer model using dual CD44/EGFR-targeting nanoparticles. Mol Ther 24: 759-769, 2016.

27. Sobin LH: TNM: Principles, history, and relation to other prognostic factors. Cancer 91 (8 Suppl): S1589-S1592, 2001.

28. Izzotti A, Calin GA, Steele VE, Croce CM and De Flora S: Relationships of microRNA expression in mouse lung with age and exposure to cigarette smoke and light. FASEB J 23: 3243-3250, 2009

29. Livak KJ and Schmittgen TD: Analysis of relative gene expression data using real-time quantitative PCR and the 2(-Delta Delta $\mathrm{C}(\mathrm{T})$ ) method. Methods 25: 402-408, 2001.

30. Quarto M, Pugliese M, La Verde G, Loffredo F and Roca V: Radon exposure assessment and relative effective dose estimation to inhabitants of puglia region, South Italy. Int J Environ Res Public Health 12: 14948-14957, 2015.

31. Naeini MM and Ardekani AM: Noncoding RNAs and cancer. Avicenna J Med Biotechnol 1: 55-70, 2009.

32. Jansson MD and Lund AH: MicroRNA and cancer. Mol Oncol 6: 590-610, 2012

33. Morey C and Avner P: Employment opportunities for non-coding RNAs. FEBS Lett 567: 27-34, 2004.

34. Rasool M, Malik A, Zahid S, Ashraf MAB, Qazi MH, Asif M, Zaheer A, Arshad M, Raza A and Jamal MS: Non-coding RNAs in cancer diagnosis and therapy. Non-coding RNA Res 1: 69-76, 2016.

35. Inamura K: Major tumor suppressor and oncogenic non-coding RNAs: Clinical relevance in lung cancer. Cells 6: pii: E12, 2017.

36. Christopher AF, Kaur RP, Kaur G, Kaur A, Gupta V and Bansa P: MicroRNA therapeutics: Discovering novel targets and developing specific therapy. Perspect Clin Res 7: 68-74, 2016

37. Inamura K: Diagnostic and therapeutic potential of MicroRNAs in lung cancer. Cancers (Basel) 9: pii: E49, 2017

38. Inamura $\mathrm{K}$ and Ishikawa Y: MicroRNA in lung cancer: Nove biomarkers and potential tools for treatment. J Clin Med 5: pii: E36, 2016.

39. Ottman R, Levy J, Grizzle WE and Chakrabarti R: The other face of miR-17-92a cluster, exhibiting tumor suppressor effects in prostate cancer. Oncotarget 7: 73739-73753, 2016.

40. Wu Q, Yang Z, Wang F, Hu S, Yang L, Shi Y and Fan D: $\mathrm{MiR}-19 \mathrm{~b} / 20 \mathrm{a} / 92 \mathrm{a}$ regulates the self-renewal and proliferation of gastric cancer stem cells. J Cell Sci 126: 4220-4229, 2013.

41. Li J, Yang S, Yan W, Yang J, Qin YJ, Lin XL, Xie RY, Wang SC, Jin W, Gao F, et al: MicroRNA-19 triggers epithelial-mesenchymal transition of lung cancer cells accompanied by growth inhibition. Lab Invest 95: 1056-1070, 2015.

42. Molinari C, Salvi S, Foca F, Teodorani N, Saragoni L, Puccetti M, Passardi A, Tamberi S, Avanzolini A, Lucci E and Calistri D: miR-17-92a-1 cluster host gene (MIR17HG) evaluation and response to neoadjuvant chemoradiotherapy in rectal cancer. Onco Targets Ther 9: 2735-2742, 2016

43. Zhou X, Wen W, Shan X, Zhu W, Xu J, Guo R, Cheng W, Wang F, Qi LW, Chen Y, et al: A six-microRNA panel in plasma was identified as a potential biomarker for lung adenocarcinoma diagnosis. Oncotarget 8: 6513-6525, 2017.

44. Hu W, Jin P, Ding C and Liu W: miR-19a/b modulates lung cancer cells metastasis through suppression of MXD1 expression. Oncol Lett 12: 1901-1905, 2016.

45. Stayner L, Bena J, Sasco AJ, Smith R, Steenland K, Kreuzer M and Straif K: Lung cancer risk and workplace exposure to environmental tobacco smoke. Am J Public Health 97: 545-551, 2007.

46. Field RW and Withers BL: Occupational and environmental causes of lung cancer. Clin Chest Med 33: 681-703, 2012.

47. Inamura $K$, Ninomiya $H$, Nomura $K$, Tsuchiya E, Satoh $Y$, Okumura S, Nakagawa K, Takata A, Kohyama N and Ishikawa Y: Combined effects of asbestos and cigarette smoke on the development of lung adenocarcinoma: Different carcinogens may cause different genomic changes. Oncol Rep 32: 475-482, 2014.

48. Bersimbaev RI and Bulgakova O: The health effects of radon and uranium on the population of Kazakhstan. Genes Environ 37: 18, 2015.

49. National Research Council: (US) Committee on health risks of exposure to radon (BEIR VI). Health effects of exposure to radon: BEIR VI. Washington (DC), National academies press (US), 1999. Available from: https://www.ncbi.nlm.nih. gov/books/NBK233262/. 
50. Shi B, Gao H, Zhang T and Cui Q: Analysis of plasma microRNA expression profiles revealed different cancer susceptibility in healthy young adult smokers and middle-aged smokers. Oncotarget 7: 21676-21685, 2016.

51. Gross TJ, Powers LS, Boudreau RL, Brink B, Reisetter A, Goel K, Gerke AK, Hassan IH and Monick MM: A microRNA processing defect in smokers' macrophages is linked to SUMOylation of the endonuclease DICER. J Biol Chem 289: 12823-12834, 2014.

52. Izzotti A, Balansky R, Ganchev G, Iltcheva M, Longobardi M, Pulliero A, Geretto M, Micale RT, La Maestra S, Miller MS, et al: Blood and lung microRNAs as biomarkers of pulmonary tumorigenesis in cigarette smoke-exposed mice. Oncotarget 7: 84758-84774, 2016.

53. Izzotti A and Pulliero A: The effects of environmental chemical carcinogens on the microRNA machinery. Int J Hyg Environ Health 217: 601-627, 2014.

54. Balansky R, Izzotti A, D'Agostini F, Longobardi M, Micale R, La Maestra S, Camoirano A, Ganchev G, Iltcheva M, Steele VE and De Flora S: Assay of lapatinib in murine models of cigarette smoke carcinogenesis. Carcinogenesis 35: 2300-2307, 2014.

55. Jarry J, Schadendorf D, Greenwood C, Spatz A and van Kempen LC: The validity of circulating microRNAs in oncology: Five years of challenges and contradictions. Mol Oncol 8: 819-829, 2014

56. Johnson CD, Esquela-Kerscher A, Stefani G, Byrom M, Kelnar K Ovcharenko D, Wilson M, Wang X, Shelton J, Shingara J, et al: The let-7 microRNA represses cell proliferation pathways in human cells. Cancer Res 67: 7713-7722, 2007.

57. Mendell J: miRiad roles for the miR-17-92 cluster in development and disease. Cell 133: 217-222, 2008.

58. Lu Y, Thomson JM, Wong HY, Hammond SM and Hogan BL: Transgenic over-expression of the microRNA miR-17-92 cluster promotes proliferation and inhibits differentiation of lung epithelial progenitor cells. Dev Biol 310: 442-453, 2007.
59. Lee HJ, Guo HY, Lee SK, Jeon BH, Jun CD, Lee SK, Park MH and Kim EC: Effects of nicotine on proliferation, cell cycle, and differentiation in immortalized and malignant oral keratinocytes. J Oral Pathol Med 34: 436-443, 2005.

60. Ng TK, Huang L, Cao D, Yip YW, Tsang WM, Yam GH, Pang CP and Cheung HS: Cigarette smoking hinders human periodontal ligament-derived stem cell proliferation, migration, and differentiation potentials. Sci Rep 5: 7828, 2015

61. Vogelstein B, Lane D and Levine AJ: Surfing the p53 network. Nature 408: 307-310, 2000

62. Fischer M: Census and evaluation of p53 target genes. Oncogene 36: 3943-3956, 2017.

63. Pflaum J, Schlosser S and Müller M: p53 family and cellular stress responses in cancer. Front Oncol 4: 285, 2014.

64. Uramoto H, Sugio K, Oyama T, Nakata S, Ono K, Nozoe T and Yasumoto K: Expression of the p53 family in lung cancer. Anticancer Res 26: 1785-1790, 2006.

65. Hasbek Z, Doğan ÖT, Sarı İ, Yücel B, Seker MM, Turgut B, Berk S and Silig Y: The diagnostic value of the correlation between serum Anti-p53 antibody and positron emission tomography parameters in lung cancer. Mol Imaging Radionucl Ther 25: 107-113, 2016.

66. Ruano-Ravina A, Pérez-Becerra R, Fraga M, Kelsey KT and Barros-Dios JM: Analysis of the relationship between p53 immunohistochemical expression and risk factors for lung cancer, with special emphasis on residential radon exposure. Ann Oncol 19: 109-114, 2008.

67. Schneider J, Presek P, Braun A and Woitowitz H: Serum levels of pantropic p53 protein and EGF-receptor, and detection of anti-p53 antibodies in former uranium miners (SDAG Wismut). Am J Ind Med 36: 602-609, 1999. 